\title{
EL PROBLEMA DE LA REALIDAD EN EL QUIJOTE
}

EI primero que planteó seriamente el problema de la realidad en las obras cervantinas fué, si no me equivoco, Américo Castro. En su magnífico libro El pensamiento de Cervantes (Madrid, 1925) dice al respecto lo siguiente: "Si hay en Cervantes una preocupación general, previa a las demás, es la de cómo sea la realidad objetiva" (pág. 79). Y también: "Don Quijote es el depositario mayor del tema de la realidad oscilante" (pág. 8o). Desde entonces, tanto en nuestras aulas como en nuestros escritos, ¿cuántos profesores no hemos repetido que en el Quijote Cervantes se proponía, amén de otras muchas cosas, sondear la naturaleza de la realidad? Pero he aquí que en 1947 vuelve don Américo sobre el tema y dice:

Hace años intenté interpretar el Quijote con criterios excesivamente occidentales, y creí que a Cervantes le interesaba en ocasiones determinar cuál fuera la realidad yacente bajo la fluctuación de las apariencias. Mas no es el problema de la verdad o del error lógico lo que al autor preocupa, sino hacer sentir cómo la realidad es siempre un aspecto de la experiencia de quien la está viviendo ${ }^{1}$.

Este cambio de punto de vista de parte de tan profundo conocedor del Quijote como Castro parece justificar, si necesita justificarse, que se examine de nuevo el problema de la realidad en la obra máxima de Cervantes.

Sea como sea la realidad en el mundo de la vida, por lo general es de una consistencia ejemplar en el mundo del Quijote. Ahora que me doy cuenta de ello, me pregunto cómo hemos podido hablar tanto de su carácter problemático. Sin duda es porque en las aventuras más comentadas del Quijote el caballero ve gigantes donde su

${ }^{1}$ Miguel de Cervantes Saavedra, Homenaje de Insula en el cuarto centenario de su nacimiento, 1547-1947, [Madrid, 1947] pág. 35. Pero la antigua actitud persiste. Véase, por ejemplo, A. F. G. Bell, Cervantes, Norman, Oklahoma, 1947. En este libro hay un capítulo llamado "The probing of reality". He aquí una muestra de la actitud de Bell ante nuestro tema: "A lo largo de las obras de Cervantes se manifiesta un continuo poner a prueba las cosas, la búsqueda de un sólido lecho de roca en el cual fincar los cimientos de la verdad" (pág. 118 ). 
escudero ve molinos, es decir, don Quijote ve el plano ideal de la realidad, y Sancho el plano real. Y, claro está, si la realidad presenta dos planos, este solo hecho basta para que se plantee el problema de la verdadera naturaleza de la realidad, problema que, por otra parte, nos halagaba plantear, porque nos permitía colocar a Cervantes en la vanguardia de nuevas actitudes filosóficas. Lo malo de este razonamiento consiste en desatender muchos episodios del Quijote en que los llamados realistas se conducen cómo idealistas, y los supuestos idealistas como realistas ${ }^{2}$. El ver esto sugiere que las complicaciones no están en la realidad sino en la cabeza y en el alma del hombre. Si hay, por lo que se refiere a la realidad, una distinción generalmente válida para todo el Quijote, es la que separa la realidad tal como se la presenta Cervantes al lector de la realidad tal como la ven o interpretan los personajes de su libro. Voy a asentar mi análisis del problema sobre esta distinción.

Vuelva el lector, si quiere, a considerar, libre de los prejuicios de otros comentarios, las principales aventuras de la Primera Parte?. Verá que no hay motivo para dudar de la realidad objetiva de molinos, frailes benitos, vizcaíno, yangüeses, moro encantado, rebaños, cuerpo muerto, batanes, etc. Aun cuando las aventuras se inician

\footnotetext{
${ }^{2}$ Son muchos los críticos que no tienen en cuenta este fenómeno y que siguen insistiendo en dualismos representados por don Quijote y Sancho. Recordemos tres ejemplos recientes: "En su libro inmortal, Cervantes llega a tan excepcional acierto, expresando por boca del Quijote [sic] el ideal, y por la de Sancho, lo real, y así, su arte imperecedero es idealista y realista a la vez, en síntesis maravillosa no superada" (Oscar Miró Quesada, "Dualidad en Cervantes y en el Quijote", en $R F E$, XXXII, 1948, pág. 410). "El uno [don Quijote] es el prototipo del hombre doctrinario; el otro [Sancho Panza], el símbolo del hombre oportunista. El uno es la sindéresis sin la prudencia que la complete; el otro es la prudencia sin la sindéresis que la incoe. Y por eso, ni uno ni otro son figuras completas sino entes paradójicos y mutilados, que sólo pueden darse con pureza en el terreno de las fábulas" (Leopoldo Eulogio Palacios, "La significación doctrinal del Quijote", en RFE, XXXII, 1948, pág. 313). En la última edición de su Historia de la literatura española (Barcelona, 1950), Valbuena Prat sigue insistiendo: "La dualidad gigantes-molinos definirá para siempre el carácter de las dos figuras" (vol. II, pág. 69). Me parece que estos dualismos son fatales para la buena comprensión de la novela de Cervantes. En su Sentido y forma del Quijote, Madrid, 1949, J. Casaldukro expresa con precisión "la exacta relación de don Quijote y Sancho, los cuales ni se oponen ni se complementan, sino que representan dos valores distintos del mismo mundo ideal: Dulcinea, la Insula" (pág. 44).

${ }^{3}$ Para estudiar el tema de la realidad, las aventuras de la Primera Parte me parecen más significativas que las de la Segunda, porque las más de éstas son aventuras que los demás personajes crean deliberadamente a don Quijote. Es decir que son engaños, y no parece plausible que Cervantes creyera que el engaño deliberado revelara nada respecto a la realidad objetiva. Las aventuras de la Segunda Parte son muy importantes, eso sí, para el estudio de la ilusión y del engaño.
} 
con misterio, como la del cuerpo muerto y la de los batanes, Cervantes siempre acaba diciéndonos exactamente de qué se trata. Hasta en la prolongada y tantas veces comentada aventura del yelmo de Mambrino el narrador nos informa bien pronto que el yelmo es bacía, y no hay ni un momento en que nadie, menos don Quijote, crea que sea otra cosa. No vuelvo a estudiar estas aventuras con todos sus pelos y señales, porque ya se ha hecho en parte ${ }^{4}$, y porque existe otra manera, no aprovechada aún, para saber si Cervantes pretendía o no buscar con el lector la realidad objetiva oculta bajo la fluctuación de las apariencias.

Si los personajes del Quijote se confunden o equivocan a menudo ante las apariencias engañosas de la realidad, el narrador no se confunde ni deja que se confunda el lector. Además de contar las aventuras de tal modo que el lector sepa siempre cuál es la realidad objetiva, Cervantes se sirve de otros recursos para insistir en su verdadera naturaleza. Por ejemplo, mucho después de contada la aventura acaecida en el "estrellado establo" de la venta, se torna a aludir a "aquel moro encantado del harriero" ". Aunque el lector ya sabe que el moro encantado es el arriero, el narrador vuelve a insistir en ello. Hace lo mismo en algunas de sus famosas recapitulaciones:

-En eso - respondió el bachiller- hay diferentes opiniones, como hay diferentes gustos: unos se atienen a la aventura de los molinos de viento, que a vuestra merced le parecieron Briareos y gigantes; otros, a la de los batanes; éste, a la descripción de los dos ejércitos, que después parecieron ser dos manadas de carneros; aquél encarece la del muerto que llevaban a enterrar a Segovia; uno dice que a todas se aventaja la de la libertad de los galeotes; otro, que ninguna iguala a la de los dos gigantes benitos, con la pendencia del valeroso vizcaíno (pág. $5^{80}$ ).

En muchos de los títulos de sus capítulos anticipa Cervantes la realidad que don Quijote ha de interpretar mal. Por ejemplo, el título del capítulo viII no habla de gigantes sino de "la espantable y jamás imaginada aventura de los molinos de viento"; el del capítulo xvi habla "de lo que le sucedió al ingenioso hidalgo en la venta que él imaginaba ser castillo"; el del capítulo xxxvi alude a la batalla que don Quijote tuvo "con unos cueros de vino tinto".

" Cf. A. A. Parker, "El concepto de la verdad en el Quijote", en RFE, XXXII, 1948, págs. 287-305. Me encuentro de acuerdo con Parker en lo que se refiere a la actitud de Cervantes frente a la realidad, pero no puedo aceptar completamente su análisis del proceso del engaño, ni su interpretación del carácter de don Quijote.

“ Don Quijote de la Mancha, ed. Martín de Riquer, 2" ed., Barcelona, 1950, pág. 463. Todas las citas remitirán a esta edición. Me sirvo de una edición en un tomo para facilitar las muchas citas que necesito hacer. 
Si el lector repasa todos los títulos, verá que frecuentemente el narrador asegura la realidad antes que la deformen sus personajes.

La tendencia de Cervantes a explicarlo todo la podemos representar con una frase suya muy repetida, "y así era la verdad”. ¡Cuántas veces confirma los hechos con esta frase o con alguna variante de ella! Cuando Sancho reconoce que los ejércitos del capítulo viI son rebaños de ovejas y carneros, el autor lo confirma en el acto: "Y así era la verdad, porque ya llegaban cerca los dos rebaños" (pág. 166). Hacia el final de la Segunda Parte dice Sancho a su amo: "Y levántese vuestra merced agora para recibir a Don Gregorio; que me parece que anda la gente alborotada, y ya debe de estar en casa". Luego el autor: "Así era la verdad" (pág. 1057). Entre estos dos ejemplos se hallan muchos más ${ }^{6}$. El narrador es el árbitro de las dificultades ofrecidas por la realidad. Su estribillo "y así era la verdad" lo confirma. Si Cervantes pretendiera que el lector considerase problemática la realidad, ¿no tendría él que ocultar un poco su propia seguridad ante ella? Para él, como para el lector, la verdad de lo sucedido en el Quijote "siempre anda sobre la mentira, como el aceite sobre el agua" (pág. 624).

Nada de lo dicho arriba va encaminado a demostrar que les sea fácil a los personajes del Quijote interpretar bien la realidad. Al contrario, el Quijote demuestra de cabo a cabo lo mucho que les cuesta. Pero las complicaciones de la realidad le interesan a Cervantes menos que la actitud mental de sus personajes frente a ella. Esto lo atestigua, entre otras cosas, un rasgo estilístico no comentado hasta ahora, que yo sepa. Me refiero a lo que pudiéramos llamar "el lenguaje conjetural". No recuerdo otro libro en que abunde tanto. Veamos algunos de los numerosísimos ejemplos. Al final de la barahunda armada en el pajar de la venta, don Quijote dice a Sancho: "Por donde conjeturo" que el tesoro de la fermosura de esta doncella le debe de guardar algún encantado moro, y no debe de ser para mí" (pág. 152). Poco después el escudero le hace eco observando: "Sin duda, señor, que éste es el moro encantado, y debe de guardar el tesoro para otros, y para nosotros sólo guarda las puñadas y los candilazos" (pág. 153). Cuando el caballero señala la polvareda que encubre un ejército, Sancho observa: "A esa cuenta, dos deben de ser..., porque desta parte contraria se levanta asimesmo otra semejante polvareda" (pág. 162). Al ver cómo su amo

"Además de la frase "y así era la verdad", hay otras muchas de intención parecida: "y así fué", "como después se supo", "como, en efecto, lo eran", "el designio que tuvo Sansón ... fué hacer lo que adelante cuenta la historia". Véanse más ejemplos en las págs. 42, 59, 85, 109, 297, 362, 476, 486, 538, 611, $622,632,638,646,660,720,787,867,932,952,1013,1017,1043$.

7 Pongo en cursiva las expresiones que indican conjetura, para mejor dirigir la atención hacia ellas. 
se empeña en que la bacía sea yelmo, el escudero se impacienta y dice: "... vengo a imaginar que todo cuanto me dice de caballerías ... debe de ser cosa de viento y mentira..." (pág. 242). Al enterarse de que Dulcinea es Aldonza Lorenzo, confiesa Sancho:

... hasta aquí he estado en una grande ignorancia; que pensaba bien y fielmente que la señora Dulcinea debia de ser alguna princesa de quien vuestra merced estaba enamorado, o alguna persona tal, que mereciese los ricos presentes que vuestra merced le ha enviado, así el del vizcaíno como el de los galeotes, y otros muchos que deben ser, según deben de ser muchas las vitorias que vuestra merced ha ganado (pág. 248).

Al ver a Dorotea disfrazada de mozo, observa el cura: "Lo que vuestro traje, señora, nos niega, vuestros cabellos nos descubren: señales claras que no deben de ser de poco momento las causas que han disfrazado vuestra belleza en hábito tan indigno..." (pág. 281). Hablando de Fernando, opina Dorotea: "Todos estos recatos míos, que él debia de tener por desdenes, debieron de ser causa de avivar más su lascivo apetito..." (pág. 285). Al final de la historia de Leandra, el cabrero dice de don Quijote lo siguiente: “... para mí tengo, o que vuestra merced se burla, o que este gentilhombre debe de tener vacíos los aposentos de la cabeza" (pág. 531). Es extraordinaria la frecuencia con que se usa deber de en sentido conjetural $^{8}$. Y no es el único medio que emplea Cervantes para expresar la conjetura. El futuro y el potencial de probabilidad también abundan. Al "Muñatón" de su sobrina, contesta don Quijote: "Frestón diria" (pág. 78). A veces se combinan deber de y el futuro: "Y será, si a mano viene, que debe de estar dentro alguna compañía de representantes..." (pág. 464). Deber de y el futuro de probabilidad son los recursos más abundantes, pero hay más: los personajes "conjeturan", "coligen", "por mil señales coligen", "infieren", "sacan el ovillo por el hilo", "toman barruntos", etc. Es decir, que se pasan la vida tratando de interpretar las realidades que hallan en torno suyo. Si Cervantes está seguro de la realidad, no lo están sus personajes. Y si no lo están, es más por su tendencia a forjarse ilusiones que por lo ambiguo de la realidad misma. Veámoslo.

Don Quijote no se conforma con la monotonía de su vida de pobre hidalgo. En sus libros de caballerías busca un escape a la vida mezquina que le rodea. Se llena la cabeza de ilusiones librescas, lo

- No he citado más que unos poros ejemplos de la Prinera Parte. Hay aun más en la Segunda. Sólo en ella he contado más de ciento sesenta ejemplos. Otra palabra capital, que también contribuye a caracterizar la actitud de los personajes hacia la realidad, es parecer. Si no la comento más, es porque se han fijado en ella otros críticos. 
mismo que el ventero Juan Palomeque, pero va más lejos que éste, porque pierde el juicio. $Y$ entonces sus ilusiones se convierten en necesidades vitales, y su afán de aventuras, de fama y de justicia transforma el mundo. Se empeña en que las cosas correspondan a sus necesidades: "Yo pienso, y así es verdad, que aquel sabio Frestón que me robó el aposento y los libros ha vuelto estos gigantes en molinos por quitarme la gloria de su vencimiento" (pág. 83). Le pone en confusión el que le lleven sobre un carro de bueyes, pero su voluntad hace que se imponga a la realidad la ilusión salvadora: "Yo sé y tengo para mí que voy encantado, y esto me basta para la seguridad de mi conciencia ..." (pág. 510). Como auténtico caballero, don Quijote necesita a Dulcinea y ella es la ilusión que defenderá con más ahinco. Después de detallar su linaje para Vivaldo, exclama: "Y no se me replique en esto" (pág. 122). Cuando Sancho se entera de que Dulcinea es Aldonza Lorenzo, su amo le explica: "Y para concluir con todo, yo imagino que todo lo que digo es así, sin que sobre ni falte nada, y píntola en mi imaginación como la deseo" (pág. 250). Cuando el escudero regresa de su embajada a Dulcinea, vemos de qué terquedad es capaz el buen caballero para defender su ideal. Las observaciones de Sancho destruyen el ideal, sólo que don Quijote no lo permite. Su voluntad de creer es más fuerte que los datos presentados por Sancho. Recordemos un poco de su diálogo:

-Lo que sí sé decir - dijo Sancho- es que sentí un olorcillo algo hombruno; y debía de ser que ella, con el mucho ejercicio, estaba sudada y algo correosa.

- No sería eso - respondió don Quijote-, sino que tú debías de estar romadizado, o te debiste de oler a ti mismo; porque yo sé bien a lo que huele aquella rosa entre espinas, aquel lirio del campo, aquel ámbar desleído" (pág. 318$)^{9}$.

No es de extrañar que don Quijote se vuelva tercamente de espaldas a la realidad, porque es un iluso, pero Cervantes nos demuestra sobradamente hasta qué punto los demás también pueden ser víctimas del poder de la ilusión. Sancho, por ejemplo, se enfada con la imaginada negativa de Dulcinea antes de emprender la embajada nunca realizada: ". . . que si no responde [Dulcinea] como es razón, voto hago solene a quien puedo que le tengo de sacar la buena res-

๑ Éste es uno de los trozos comentados por Castro en su Pensamiento: "La realidad está siempre en esta doble vertiente..." (pág. 8o, nota 5). Pero Castro no dice que ni don Quijote ni Sancho tienen en cuenta la realidad, ni que Sancho miente: "Rabiaba Sancho por sacar a su amo del pueblo, porque no averiguase la mentira de la respuesta que de parte de Dulcinea le había llevado a Sierra Morena" (pág. 624). 
puesta del estómago a coces y a bofetones. Porque ¿dónde se ha de sufrir que un caballero andante, tan famoso como vuestra merced, se vuelva loco, sin qué ni para qué, por una ...? No me lo haga decir la señora ..." (pág. 252). Hasta don Quijote se da cuenta de cuán sin fundamento es el enojo de Sancho: "Así, Sancho-dijo don Quijote-, que, a lo que parece, que no estás tú más cuerdo que yo". Éste es un pasaje cómico, pero de la misma índole los hay harto serios: "Así le fatigaban a Grisóstomo los celos imaginados y las sospechas temidas como si fueran verdaderas" (pág. 130). Otro ejemplo de reacción sin base real lo encontramos al final de la historia de Leandra: “... de todos se estiende a tanto la locura, que hay quien se queje de desdén sin haberla jamas hablado, y aun quien se lamente y sienta la rabiosa enfermedad de los celos, que ella jamás dió a nadie; porque, como ya tengo dicho, antes se supo su pecado que su deseo" (pág. $\left.5^{29}\right)^{10}$.

A veces el hombre se despega de la realidad en alas de sus deseos y esperanzas. Y aun cuando comprende que sus deseos son ilusorios, sigue aferrándose a ellos. Recordemos parte de la conversación que Sancho sostuvo con el escudero del Caballero del Bosque:

... en el cual [el peligroso oficio de escudero] he incurrido segunda vez, cebado y engañado de una bolsa con cien ducados que me hallé un día en el corazón de Sierra Morena, y el diablo me pone ante los ojos aquí, allí, acá no, sino acullá, un talego lleno de doblones, que me parece que a cada paso le toco con la mano, y me abrazo con él, y lo llevo a mi casa, y echo censos, y fundo rentas, y vivo como un príncipe; y el rato que en esto pienso se me hacen fáciles y llevaderos cuantos trabajos padezco con este mentecato de mi amo, de quien sé que tiene más de loco que de caballero (págs. $65^{0}-5^{1}$ ).

El capitán cautivo se apoyaba más en tenues esperanzas de libertad que en las verdaderas circunstancias de su cautiverio: “. . . cuando en lo que fabricaba, pensaba y ponía por obra no correspondía el suceso a la intención, luego, sin abandonarme, fingía y buscaba otra esperanza que me sustentase, aunque fuese débil y flaca" (pág. 418). También Dorotea fingía esperanzas para entretener la vida que ya aborrecía (pág. 292).

A veces es el propio interés más bien que lo engañoso de la realidad lo que ciega al hombre. Así Sancho vió cabeza de gigante

${ }^{10}$ Cervantes insiste mucho en la "fuerza rabiosa de los celos" que trastorna el juicio recto, y eso aun cuando los celos no tengan fundamento. La conducta imprudente de Camila resulta de su caida en "la desesperada red de los celos" (pág. 357). Se malograron los amores de Claudia Jerónima porque "tejieron la trama de su lamentable historia las fuerzas invencibles y rigurosas de los celos" (pág. 1019). 
en lugar de cuero de vino. He aquí cómo el narrador explica su ceguedad: "Y estaba peor Sancho despierto que su amo durmiendo: tal le tenían las promesas que su amo le había hecho" (pág. 375).

Acaso la imaginación contribuya más que nada a que se engañe el hombre ${ }^{11}$. Sancho plantea y resuelve el problema de vasallos negros que no existen sino en su imaginación. Ye hemos aludido a los celos imaginados de Grisóstomo. La historia de Cardenio está aún más llena de frases que insisten en el poder de imaginaciones y temores para turbar la vista y entorpecer la acción. Veamos un par de ejemplos: "... se me trasluce que la fuerza de la imaginación de mis desgracias es tan intensa y puede tanto en mi perdición, que, sin que yo pueda ser parte a estorbarlo, vengo a quedar como piedra, falto de todo buen sentido y conocimiento..." (pág. 267). "En fin, yo me partí triste y pensativo, llena el alma de imaginaciones y sospechas, sin saber lo que sospechaba ni imaginaba..." (pág. 270). Dorotea salió de su casa, acompañada de su criado y "de muchas imaginaciones" (pág. 29o). A veces el hombre se mete en un "laberinto de imaginaciones" (pág. 508) de imposible salida. Buen ejemplo es Anselmo. De él se dice casi al final de su vida: "Viéndose, pues, solo, comenzó a cargar tanto la imaginación de su desventura, que claramente conoció que se le iba acabando la vida..." (pág. 380).

No es tanto que la realidad sea un enigma imposible de descifrar, sino que el hombre no ha de dejarse vencer de la verdad ni de la razón. Recordemos lo que de Sancho se dice al final de la batalla con el Caballero de los Espejos: “... mas la aprehensión que en Sancho había hecho lo que su amo dijo de que los encantadores habían mudado la figura del Caballero de los Espejos en la del bachiller Carrasco no le dejaba dar crédito a la verdad, que con los ojos estaba mirando" (pág. 665). Cardenio no quiere oír la voz de la razón: ". . no os canséis en persuadirme ni aconsejarme lo que la razón os dijere ... Yo no quiero salưd sin Luscinda ..." (pág. 278). El desafiar a la razón puede conducir a la locura. Anselmo confiesa la suya (pág. 337), y la define con toda exactitud: “. . y ansimesmo veo y confieso que si no sigo tu parecer y me voy tras el mío, voy huyendo del bien y corriendo tras el mal" (pág. 346). Anselmo sabe que no es razonable su conducta, pero no por eso deja de rodar por la pendiente de su locura.

Las ilusionnes pueden originarse en deseos, esperanzas, temores,

${ }^{11}$ Imaginar (y sus derivados) es otro vocablo que se usa con notable frecuencia. A veces, se encuentra en combinaciones que sugieren el papel que la imaginación desempeña en la ilusión: "desvariadas imaginaciones" (pág. 295), "loca imaginación" (pág. 461), "confusa imaginación" (pág. 487), "envuelto y revuelto cn estas y otras muchas imaginaciones” (pág. 579), etc. 
intereses, imaginaciones e innumerables estímulos más. Pueden sostenerse a fuerza de pura voluntad. Cuando el ama y la sobrina tratan de estorbar la tercera salida de don Quijote, éste les dice: “... será en balde cansaros en persuadirme a que no quiera yo lo que los cielos quieren, la fortuna ordena y la razón pide, y, sobre todo, mi voluntad desea..." (pág. 6o4). Otro elocuente ejemplo de ilusión voluntaria lo vemos en los amores de don Quijote y Anselmo. Los dos quieren servir a una dama excelsa. Con igual empeño e igual descuido de la realidad, el uno la crea y encumbra, y el otro la aniquila. Una vez arraigada la ilusión, puede ejercer una fuerza irresistible. Puede matar; ya lo hemos visto. Puede disponer a los poseídos a morir por ella. Así, cara a la muerte, dirá don Quijote: "Dulcinea del Toboso es la más hermosa mujer del mundo, y yo el más desdichado caballero de la tierra, y no es bien que mi flaqueza defraude esta verdad. Aprieta, caballero, la lanza, y quítame la vida, pues me has quitado la honra" (pág. 1053) ${ }^{12}$. Y eso a pesar de haber confesado mucho antes: "Dios sabe si hay Dulcinea o no en el mundo, o si es fantástica o no es fantástica" (pág. 809) .

En las páginas que preceden hemos visto una muestra de la realidad tal como es -visión de Cervantes-, y una muestra de la realidad tal como puede parecer -visión de sus personajes ${ }^{13}$. Creo que hemos visto también que si no se ajustan estas dos visiones, es por la ineluctable propensión de los personajes a forjarse ilusiones. ¡Cómo podemos creer que a Cervantes le interesaba sugestionar al lector con lo problemático de la realidad, cuando él se muestra tan seguro ante ella! iY cómo íbamos a reírnos de las equivocaciones de los personajes, si nadie puede saber cuál es la realidad! Si no hay realidad, no hay error. ¿No es evidente, pues, que Cervantes no quería plantear el problema de la realidad sino el problema del hombre frente a ella, del hombre tan propenso a ver la realidad en el espejo deformante de sus ilusiones? Creo que Castro anda ahora mucho más cerca de la verdad cuando dice que la realidad es un aspecto de la experiencia de quien la está viviendo ${ }^{14}$. Tal vez sea todavía excesiva

1: Por esta ve\% no atribuye don Quijote su derrota al encantamiento, sino a su propia flaqueza. A Sancho, sin embargo, el supuesto realista, "parecíale que todo aquel suceso pasaba en sueños y que toda aquella máquina era cosa de encantamiento" (págs. 1053-54).

${ }^{13}$ No hay que decir que me refiero exclusivamente a la realidad tal como figura en el Quijote. No pretendo resolver viejos problemas filosóficos.

it Para comprender a fondo las nuevas ideas de Castro habrá que esperar, como él mismo dice, su nuevo libro sobre Cervantes. Por ahora veo cosas que no acaban de convencer. Por ejemplo, poco después de hablar de la realidad como aspecto de la experiencia, dice esto: "Mas lo nuevo en el Quijote consistió en hacer valer como verdadero lo auténticamente enlazado con una experiencia vital, y no lo determinado por un proceso cognoscitivo" (en el citado Homenaje de insula, pág. 35). Como he dejado ver en este artículo, no creo 
la insistencia en la realidad. Como buen español, Cervantes se interesaba mucho más por el hombre vivo que por la realidad objetiva. $Y$ esta insistencia en los procesos vitales del hombre contribuye a la perenne vitalidad de su obra máxima. Las actitudes filosóficas (idealista, relativista, positivista, etc.) pueden variar de época en época, pero todas las épocas seguirán interesándose por el hombre ocupado. en su eterno negocio, el de interpretar la realidad en que ha de vivir.

Duke University.

Richard I. PREDNioke

que a Cervantes le interesara hacer valer como verdadero lo cnlazado con una experiencia vital. La experiencia vital si le interesaba mucho. y por ilusoria que fuera. 